\title{
Fixed Point Results for Weak $\varphi$-Contractions in Cone Metric Spaces over Banach Algebras and Applications
}

\author{
Biwen $\mathrm{Li}^{1}$ and Huaping Huang ${ }^{2}$ \\ ${ }^{1}$ School of Mathematics and Statistics, Hubei Normal University, Huangshi 435002, China \\ ${ }^{2}$ School of Mathematical Sciences, Beijing Normal University, Laboratory of Mathematics and Complex Systems, Ministry of Education, \\ Beijing 100875, China
}

Correspondence should be addressed to Huaping Huang; mathhhp@163.com

Received 8 October 2017; Accepted 26 November 2017; Published 13 December 2017

Academic Editor: Manuel De la Sen

Copyright (C) 2017 Biwen Li and Huaping Huang. This is an open access article distributed under the Creative Commons Attribution License, which permits unrestricted use, distribution, and reproduction in any medium, provided the original work is properly cited.

By using a nontrivial proof method, the purpose of this paper is to obtain some fixed point results for weak $\varphi$-contractions in cone metric spaces over Banach algebras. Several examples and applications to the existence and uniqueness of a solution to two classes of equations are also given.

\section{Introduction}

Fixed point theory is without doubt one of the most important tools of modern mathematics as attested by Browder [1] who is considered as one of the pioneers in the development of the nonlinear functional analysis. The flourishing field of fixed point theory started in the early days of topology through the work of Poincaré [2], Lefschetz-Hopf, and LeraySchauder, for example. Fixed point theory is widely used in different areas such as ordinary and partial differential equations, economics, logic programming, convex optimization, and control theory. In metric fixed point theory, successive approximations are rooted in the work of Cauchy, Fredholm, Liouville, Lipschitz, Peano, and Picard. It is well accepted among experts of this subarea that Banach is responsible for laying the ground for an abstract framework well beyond the scope of elementary differential and integral equations. In 1922, Banach [3] proved the most influential and celebrating fixed point theorem, which was Banach fixed point theorem (i.e., Banach contraction principle). Since then, fixed point theory has had a rapid development. In [4], Huang and Zhang introduced cone metric space and generalized Banach fixed point theorem in such spaces. Subsequently, many people were interested in fixed point results in cone metric spaces (see [5-10] and the references therein). In [11-13], Rus and Berinde introduced the notion of $\varphi$-contraction and also generalized Banach fixed point theorem in usual metric spaces. Recently, Liu and $\mathrm{Xu}$ [14] introduced the concept of a cone metric space over Banach algebra, which is an interesting generalization of classic metric spaces. From then on, many authors focused on the investigation of fixed point in such spaces (see [15-20]). Stimulated and motivated by the previous work, throughout this paper, we introduce weak $\varphi$-contractions in the setting of cone metric spaces over Banach algebras and present some fixed point theorems for weak $\varphi$-contractions. Our results improve and weaken the conditions of the vector-valued version of Banach fixed point theorem. To the best of our knowledge, our methods are new. In addition, by using our results, we give the existence and uniqueness of a solution to elementary equations and to integral equations.

The following notions and facts will be needed in this paper.

Definition 1 (see [12]). A function $\varphi:[0, \infty) \rightarrow[0, \infty)$ is called a comparison if it satisfies the following two conditions:

(1) $\varphi$ is monotone nondecreasing; that is, $0 \leq t_{1} \leq t_{2} \Rightarrow$ $\varphi\left(t_{1}\right) \leq \varphi\left(t_{2}\right)$.

(2) $\left\{\varphi^{n}(t)\right\}(t>0)$ converges to 0 as $n \rightarrow \infty$.

Remark 2. By Definition 1, it is sufficient to get that $\varphi(t)<t$ for each $t>0, \varphi(0)=0$, and $\lim _{t \rightarrow 0} \varphi(t)=0$. 
Definition 3 (see [12]). Let $(X, d)$ be a metric space. A mapping $T: X \rightarrow X$ is called a $\varphi$-contraction if there exists a comparison $\varphi:[0, \infty) \rightarrow[0, \infty)$ such that

$$
d(T x, T y) \leq \varphi(d(x, y)) \quad(\forall x, y \in X) .
$$

The following theorem generalizes Banach fixed point theorem.

Theorem 4 (see [12]). Let $(X, d)$ be a metric space and $T$ : $X \rightarrow X$ be a $\varphi$-contraction. Then $T$ has a unique fixed point in $X$. Moreover, for any $x \in X$, the iterative sequence $\left\{T^{n} x\right\}$ converges to the fixed point.

In the following, we consider our results in the framework of cone metric spaces over Banach algebras. For the reader who is unfamiliar with cone metric space over Banach algebra, we recall some of its notions and results as follows.

Definition 5 (see [14]). Let $\mathscr{A}$ be a Banach algebra with a unit $e$ and a zero element $\theta$. A nonempty closed subset $P$ of $\mathscr{A}$ is called a cone if the following conditions hold:

(1) $\{\theta, e\} \subset P$.

(2) $\forall \alpha, \beta \in[0, \infty) \Rightarrow \alpha P+\beta P \subseteq P$.

(3) $P^{2}=P P \subset P$.

(4) $P \cap(-P)=\{\theta\}$.

A cone $P$ is called a solid cone if int $P \neq \emptyset$, where int $P$ stands for the interior of $P$.

On this basis, we define a partial ordering $\preceq$ with respect to $P$ by $x \preceq y$ if and only if $y-x \in P$. We shall write $x \ll y$ to indicate that $y-x \in \operatorname{int} P$. We shall also write $\|\cdot\|$ as the norm on $\mathscr{A}$. A cone $P$ is called normal if there is a number $K>0$ such that, for all $x, y \in \mathscr{A}, \theta \preceq x \preceq y$ implies $\|x\| \leq K\|y\|$.

In the sequel, unless otherwise specified, we always suppose that $\mathscr{A}$ is a Banach algebra with a unit $e, P$ is a solid cone in $\mathscr{A}$, and $\preceq$ and $\ll$ are partial orderings with respect to $P$. We always write $\mathbb{N}$ and $\mathbb{R}$ as the set of all natural numbers and the set of all real numbers, respectively.

Definition 6 (see [14]). Let $X$ be a nonempty set and $\mathscr{A}$ be a Banach algebra. A mapping $d: X \times X \rightarrow \mathscr{A}$ is called a cone metric if it satisfies

(i) $\theta \preceq d(x, y)(\forall x, y \in X), d(x, y)=\theta \Leftrightarrow x=y$;

(ii) $d(x, y)=d(y, x)(\forall x, y \in X)$;

(iii) $d(x, y) \preceq d(x, z)+d(z, y)(\forall x, y, z \in X)$.

In this case, the pair $(X, d)$ is called a cone metric space over Banach algebra.

Definition 7 (see [8]). A sequence $\left\{u_{n}\right\}$ in a Banach algebra $\mathscr{A}$ is said to be a $c$-sequence if, for each $c \gg \theta$, there exists $N \in \mathbb{N}$ such that $u_{n} \ll c$ for all $n>N$.

The introduction of $c$-sequence is an interesting increase since, by using $c$-sequence, many intricate concepts may be simplified. For example, Definitions 2-4 of [4] are abbreviated with the following.
Definition 8 (see [17]). Let $(X, d)$ be a cone metric space over Banach algebra $\mathscr{A}$ and $\left\{x_{n}\right\}$ be a sequence in $X$. We say that

(i) $\left\{x_{n}\right\}$ converges to $x \in X$ if $\left\{d\left(x_{n}, x\right)\right\}$ is a $c$-sequence;

(ii) $\left\{x_{n}\right\}$ is a Cauchy sequence if $\left\{d\left(x_{n}, x_{m}\right)\right\}$ is a $c$ sequence for $n, m$;

(iii) $(X, d)$ is complete if every Cauchy sequence in $X$ is convergent.

Lemma 9 (see [9]). Let $\mathscr{A}$ be a Banach algebra and $u, v, w \in$ A. Then

(1) $u \ll w$ if $u \preceq v \ll w$ or $u \ll v \preceq w$;

(2) $u=\theta$ if $\theta \preceq u \ll c$ for each $c \gg \theta$.

Lemma 10 (see [21]). Let $\mathscr{A}$ be a Banach algebra with its unit e. Then the spectral radius of $u \in \mathscr{A}$ equals $\rho(u)=$ $\lim _{n \rightarrow \infty}\left\|u^{n}\right\|^{1 / n}$

Lemma 11 (see [16]). Let $P$ be a cone in a Banach algebra $\mathscr{A}$, $\left\{u_{n}\right\}$ and $\left\{v_{n}\right\}$ be two c-sequences in $\mathscr{A}$, and $\alpha, \beta \in P$ be vectors; then $\left\{\alpha u_{n}+\beta v_{n}\right\}$ is a c-sequence in $\mathscr{A}$.

Lemma 12 (see [15]). Let $P$ be a cone and $k \in P$ with $\rho(k)<1$. Then $\left\{k^{n}\right\}$ is a c-sequence.

\section{Main Results}

In this section, we introduce weak $\varphi$-contractions in the framework of a cone metric space over Banach algebra and obtain some corresponding fixed point theorems. Moreover, we present some examples to illustrate the superiority of the results.

Definition 13. Let $\mathscr{A}$ be a Banach algebra and $P$ be a cone in $\mathscr{A}$. A mapping $\varphi: P \rightarrow P$ is called a weak comparison if the following conditions hold:

(i) $\varphi$ is nondecreasing with respect to $\preceq$; namely, $t_{1}, t_{2} \in$ $P, t_{1} \preceq t_{2} \Rightarrow \varphi\left(t_{1}\right) \preceq \varphi\left(t_{2}\right)$.

(ii) $\left\{\varphi^{n}(t)\right\}(t \in P)$ is a $c$-sequence in $P$.

(iii) if $\left\{u_{n}\right\}$ is a $c$-sequence in $P$, then $\left\{\varphi\left(u_{n}\right)\right\}$ is also a $c$ sequence in $P$.

Remark 14. By Definition 13, it suffices to show that $\varphi(\theta)=\theta$. Indeed, by (i) of Definition 13, we have $\theta \preceq \varphi(\theta) \preceq \varphi^{n}(\theta)$. Since $\left\{\varphi^{n}(\theta)\right\}$ is a $c$-sequence, then, by Lemma 9 , it may be verified that $\varphi(\theta)=\theta$.

Remark 15. If $\mathscr{A}=\mathbb{R}^{1}$ and $P=[0, \infty)$, then Definition 13 is reduced to Definition 1. In other words, Definition 13 is a generalization of Definition 1.

The following examples are trivial, whose proofs are straightforward and are therefore omitted.

Example 16. Let $\mathscr{A}$ be a Banach algebra, $P$ be a cone in $\mathscr{A}$, and $k \in P$. Take $\varphi(t)=k t(t \in P)$, where $\rho(k)<1$. Then by Lemmas 11 and $12, \varphi$ is a weak comparison. 
Example 17. Let $M$ be a compact set of $\mathbb{R}^{n}$ and $\mathscr{A}=C(M)$, where $C(M)$ denotes the set of all continuous functions on $M$. Let $P=\{u \in \mathscr{A}: u \geq 0\}$ and define a mapping $\varphi: P \rightarrow P$ by $\varphi(u)=u /(u+1)$. Then $\varphi$ is a weak comparison.

Definition 18. Let $(X, d)$ be a cone metric space over Banach algebra. Let $P$ be a cone and $\varphi: P \rightarrow P$ be a weak comparison. Then a mapping $T: X \rightarrow X$ is called a weak $\varphi$-contraction if

$$
d(T x, T y) \preceq \varphi(d(x, y)) \quad(\forall x, y \in X) .
$$

Remark 19. By Remark 15, Clearly, Definition 18 generalizes Definition 3.

The following theorem generalizes Theorem 4 and its proof method is nontrivial.

Theorem 20. Let $(X, d)$ be a complete cone metric space over Banach algebra and $T: X \rightarrow X$ be a weak $\varphi$-contraction. Then $T$ has a unique fixed point in $X$. Moreover, for any $x \in X$, the iterative sequence $\left\{T^{n} x\right\}$ converges to the fixed point.

Proof. Choose $x_{0} \in X$ and put $x_{n}=T^{n} x_{0}, n \geq 1$. For any $c \gg \theta$, by (ii) of Definition 13, there exists $n_{0} \in \mathbb{N}$ such that $\varphi^{n_{0}}(c) \ll c$. Making the most of (2), it is not hard to verify that

$$
d\left(x_{n}, x_{n+n_{0}}\right) \leq \varphi^{n}\left(d\left(x_{0}, x_{n_{0}}\right)\right) .
$$

Since $\left\{\varphi^{n}\left(d\left(x_{0}, x_{n_{0}}\right)\right)\right\}$ is a $c$-sequence, then, by Lemma 9 , $\left\{d\left(x_{n}, x_{n+n_{0}}\right)\right\}$ is also a $c$-sequence. Hence, there exists $N_{1} \in \mathbb{N}$ such that

$$
d\left(x_{n}, x_{n+n_{0}}\right) \ll c-\varphi^{n_{0}}(c) \quad\left(n \geq N_{1}\right) .
$$

Let

$$
B\left(x_{n}, c\right)=\left\{x \in X: d\left(x_{n}, x\right) \ll c\right\} \quad\left(n \geq N_{1}\right) .
$$

Choosing $x \in B\left(x_{n}, c\right)\left(n \geq N_{1}\right)$, by (3) and (5), it is established that

$$
\begin{aligned}
d\left(x_{n}, T^{n_{0}} x\right) & \leq d\left(x_{n}, x_{n+n_{0}}\right)+d\left(x_{n+n_{0}}, T^{n_{0}} x\right) \\
& \ll c-\varphi^{n_{0}}(c)+\varphi^{n_{0}}\left(d\left(x_{n}, x\right)\right) \\
& \leq c-\varphi^{n_{0}}(c)+\varphi^{n_{0}}(c)=c .
\end{aligned}
$$

This means that $B\left(x_{n}, c\right)\left(n \geq N_{1}\right)$ is $T^{n_{0}}$-invariant. Accordingly, for any $k \in \mathbb{N}$, we have $d\left(x_{n}, x_{n+k n_{0}}\right) \ll c$.

Making the best of (2), it ensures us that

$$
\begin{aligned}
& d\left(x_{n}, x_{n+1}\right)+d\left(x_{n+1}, x_{n+2}\right)+\cdots+d\left(x_{n+n_{0}-1}, x_{n+n_{0}}\right) \\
& \leq \varphi^{n}\left(d\left(x_{0}, x_{1}\right)\right)+\varphi^{n}\left(d\left(x_{1}, x_{2}\right)\right)+\cdots \\
& \quad+\varphi^{n}\left(d\left(x_{n_{0}-1}, x_{n_{0}}\right)\right) .
\end{aligned}
$$

Now that $\left\{\varphi^{n}\left(d\left(x_{i}, x_{i+1}\right)\right)\right\}\left(i=0,1, \ldots, n_{0}-1\right)$ are $c$ sequences, then, by Lemma 11, $\left\{\varphi^{n}\left(d\left(x_{0}, x_{1}\right)\right)+\varphi^{n}\left(d\left(x_{1}, x_{2}\right)\right)+\right.$ $\left.\cdots+\varphi^{n}\left(d\left(x_{n_{0}-1}, x_{n_{0}}\right)\right)\right\}$ is a $c$-sequence. Next, by Lemma 9 , $\left\{d\left(x_{n}, x_{n+1}\right)+d\left(x_{n+1}, x_{n+2}\right)+\cdots+d\left(x_{n+n_{0}-1}, x_{n+n_{0}}\right)\right\}$ is also a $c$-sequence. So, for the above $c \gg \theta$, there exists $N_{2} \in \mathbb{N}$ such that

$$
\begin{aligned}
& d\left(x_{n}, x_{n+1}\right)+d\left(x_{n+1}, x_{n+2}\right)+\cdots+d\left(x_{n+n_{0}-1}, x_{n+n_{0}}\right) \\
& \quad \ll c \quad\left(n>N_{2}\right) .
\end{aligned}
$$

Denote $N=\max \left\{N_{1}, N_{2}\right\}$, for $m, n>N$; let

$$
\begin{aligned}
k_{m} & =\left[\frac{m-N}{n_{0}}\right], \\
k_{n} & =\left[\frac{n-N}{n_{0}}\right],
\end{aligned}
$$

where $[\cdot]$ stands for the integer part. Because

$$
\begin{aligned}
& N \leq m-k_{m} n_{0}<N+n_{0}, \\
& N \leq n-k_{n} n_{0}<N+n_{0},
\end{aligned}
$$

we have

$$
\begin{aligned}
d\left(x_{m}, x_{n}\right) \preceq & d\left(x_{m}, x_{m-k_{m} n_{0}}\right)+d\left(x_{m-k_{m} n_{0}}, x_{n-k_{n} n_{0}}\right) \\
& +d\left(x_{n-k_{n} n_{0}}, x_{n}\right) \ll 3 c .
\end{aligned}
$$

Then, by Lemma 9, we claim that $\left\{x_{n}\right\}$ is a Cauchy sequence. Since $(X, d)$ is complete, then there exists $x^{*} \in X$ such that $x_{n} \rightarrow x^{*}(n \rightarrow \infty)$.

We prove that $x^{*}$ is the fixed point of $T$. Actually, by (2), we arrive at

$$
\begin{aligned}
d\left(T x^{*}, x^{*}\right) & \leq d\left(T x^{*}, x_{n}\right)+d\left(x_{n}, x^{*}\right) \\
& =d\left(T x^{*}, T x_{n-1}\right)+d\left(x_{n}, x^{*}\right) \\
& \leq \varphi\left(d\left(x^{*}, x_{n-1}\right)\right)+d\left(x^{*}, x_{n}\right) .
\end{aligned}
$$

Now that $\left\{d\left(x^{*}, x_{n-1}\right)\right\}$ is a $c$-sequence, it follows immediately from (iii) of Definition 13 that $\left\{\varphi\left(d\left(x^{*}, x_{n-1}\right)\right)\right\}$ is a $c$-sequence. Thus, by Lemma 11, we speculate that $\left\{\varphi\left(d\left(x^{*}, x_{n-1}\right)\right)+d\left(x^{*}, x_{n}\right)\right\}$ is also a $c$-sequence. Next by Lemma 9 , it may be verified that $d\left(T x^{*}, x^{*}\right)=\theta$; that is, $T x^{*}=x^{*}$.

Finally, we prove that the fixed point is unique. Assume that $y^{*}$ is another fixed point of $T$; then, by (2) and the monotonicity of $\varphi$, we deduce that

$$
d\left(x^{*}, y^{*}\right)=d\left(T^{n} x^{*}, T^{n} y^{*}\right) \leq \varphi^{n}\left(d\left(x^{*}, y^{*}\right)\right) .
$$

Since $\left\{\varphi^{n}\left(d\left(x^{*}, y^{*}\right)\right)\right\}$ is a $c$-sequence, then, by Lemma 9 , it is obvious that $d\left(x^{*}, y^{*}\right)=\theta$. As a result, $x^{*}=y^{*}$.

Corollary 21. Let $(X, d)$ be a complete cone metric space over Banach algebra $\mathscr{A}$ and $P$ be a cone in $\mathscr{A}$. Suppose that $k \in P$ and $T: X \rightarrow X$ is a mapping satisfying

$$
d(T x, T y) \leq k d(x, y) \quad(\forall x, y \in X) .
$$

If $\rho(k)<1$, then $T$ has a unique fixed point in X. Moreover, for any $x \in X$, the iterative sequence $\left\{T^{n} x\right\}$ converges to the fixed point. 
Proof. Let $\varphi(t)=k t(t \in P)$; then, by Theorem 20, we get the desired result.

Remark 22. Corollary 21 is called the vector-valued version of Banach fixed point theorem. It generalizes Theorem 2.1 of [14] because it deletes the assumption of normality of cones of Theorem 2.1 of [14].

The following example shows the superiority of Theorem 20

Example 23. Under the conditions of Example 17, let $X=\mathscr{A}$ and define a mapping $d: X \times X \rightarrow \mathscr{A}$ by $d(u, v)=|u-v|$. Then $(X, d)$ is a complete cone metric space over Banach algebra. Define a mapping $T: X \rightarrow X$ by

$$
T u=\frac{|u|}{|u|+1} \quad(u \in X) .
$$

Clearly, $T$ is not a contraction; that is, there is no $k \in \mathscr{A}$ with $\rho(k)<1$ such that the contractive condition of Theorem 2.1 of [14] holds.

However, for all $u, v \in X$, we have

$$
\begin{aligned}
d(T u, T v) & =\left|\frac{|u|}{|u|+1}-\frac{|v|}{|v|+1}\right| \leq \frac{|u-v|}{|u-v|+1} \\
& =\frac{d(u, v)}{d(u, v)+1} .
\end{aligned}
$$

By Example 17, we know that $T$ is a weak $\varphi$-contraction and then, by Theorem 20, $T$ has a unique fixed point.

\section{Applications}

In this section, we give some applications to prove the existence and uniqueness of a solution to some equations. First of all, we consider the following elementary equations:

$$
\begin{aligned}
& x=\sinh ^{-1}(\lambda x), \\
& y=\lambda \arctan |y|+\sin x,
\end{aligned}
$$

where $0<\lambda<1$ is a constant.

Theorem 24. The elementary equation (17) has a unique solution in $\mathbb{R}^{2}$.

Proof. Let $\mathscr{A}=X=\mathbb{R}^{2}$ and $P=\left\{\left(u_{1}, u_{2}\right) \in \mathscr{A}: u_{1}, u_{2} \geq 0\right\}$. Take $u=\left(u_{1}, u_{2}\right), v=\left(v_{1}, v_{2}\right) \in \mathscr{A}$. Define a norm of $\mathscr{A}$ by $\left\|\left(u_{1}, u_{2}\right)\right\|=\left|u_{1}\right|+\left|u_{2}\right|$. Define a multiplication of $\mathscr{A}$ by

$$
u v=\left(u_{1}, u_{2}\right)\left(v_{1}, v_{2}\right)=\left(u_{1} v_{1}, u_{1} v_{2}+u_{2} v_{1}\right) \text {. }
$$

For any $x=\left(x_{1}, x_{2}\right), y=\left(y_{1}, y_{2}\right) \in X$, define a mapping $d: X \times X \rightarrow \mathscr{A}$ by

$$
d(x, y)=\left(\left|x_{1}-y_{1}\right|,\left|x_{2}-y_{2}\right|\right)
$$

then $(X, d)$ is a complete cone metric space over Banach algebra. Define a mapping $T: X \rightarrow X$ by

$$
\begin{aligned}
T x & =T\left(x_{1}, x_{2}\right) \\
& =\left(\sinh ^{-1}\left(\lambda x_{1}\right), \lambda \arctan \left|x_{2}\right|+\sin x_{1}\right) .
\end{aligned}
$$

For all $x, y \in X$, by mean value theorem of differentials, there exists $\xi$ belonging to numbers between $x_{2}$ and $y_{2}$, such that

$$
\begin{aligned}
& d(T x, T y)=d\left(T\left(x_{1}, x_{2}\right), T\left(y_{1}, y_{2}\right)\right) \\
& \quad=\left(\left|\sinh ^{-1}\left(\lambda x_{1}\right)-\sinh ^{-1}\left(\lambda y_{1}\right)\right|,\right. \\
& \left.|\lambda \arctan | x_{2}|-\lambda \arctan | y_{2}\left|+\sin x_{1}-\sin y_{1}\right|\right) \\
& \quad \leq\left(\lambda\left|x_{1}-y_{1}\right|, \frac{\lambda}{1+|\xi|^{2}}\left|x_{2}-y_{2}\right|+\left|x_{1}-y_{1}\right|\right) \\
& \quad \leq(\lambda, 1)\left(\left|x_{1}-y_{1}\right|,\left|x_{2}-y_{2}\right|\right)=(\lambda, 1) d(x, y) .
\end{aligned}
$$

Choose $\varphi(u)=k u$ with $k=(\lambda, 1)$. Clearly, $\varphi$ is a weak comparison. Thus, $T$ is a weak $\varphi$-contraction. By Theorem 20, $T$ has a unique fixed point in $X$. That is to say, the elementary equation (17) has a unique solution in $\mathbb{R}^{2}$.

Secondly, we prove an existence theorem for a solution of the following nonlinear integral equation by using our results in the previous section.

$$
x(c)=\phi(c)+\int_{a}^{b} K(c, t, x(t)) \mathrm{d} t,
$$

where $a, b \in \mathbb{R}, x \in C[a, b]$ (the set of all continuous functions from $[a, b]$ into $\mathbb{R}), \phi:[a, b] \rightarrow \mathbb{R}$, and $K:[a, b] \times$ $[a, b] \times \mathbb{R} \rightarrow \mathbb{R}$ are given mappings.

Theorem 25. Let $L^{p}[a, b]=\left\{x=x(t): \int_{a}^{b}|x(t)|^{p} d t<\right.$ $\infty\}(p \geq 1)$. If there exists $M>0$ with $M(b-a)^{1 / p}<1$ such that, for all $x, y \in L^{p}[a, b]$ and $c \in[a, b]$,

$$
|K(c, t, x(t))-K(c, t, y(t))| \leq M|x(t)-y(t)|^{p},
$$

then the integral equation (22) has a unique solution in $L^{p}[a$, $b]$.

Proof. Let $\mathscr{A}=\mathbb{R}^{2}$ with the same norm, the same multiplication, and the same cone $P$ as stated in the proof of Theorem 24. Then $P$ is a normal cone and $\mathscr{A}$ is a Banach algebra with a unit $e=(1,0)$. Let $X=L^{p}[a, b]$. We endow $X$ with the cone metric

$$
\begin{gathered}
d(x, y)=\left(\left\{\int_{a}^{b}|x(c)-y(c)|^{p} \mathrm{~d} c\right\}^{1 / p},\right. \\
\left.\left\{\int_{a}^{b}|x(c)-y(c)|^{p} \mathrm{~d} c\right\}^{1 / p}\right)
\end{gathered}
$$

for all $x, y \in X$. It is clear that $(X, d)$ is a complete cone metric space over Banach algebra $\mathscr{A}$. Define the mapping $T: X \rightarrow X$ by

$$
T x(c)=\phi(c)+\int_{a}^{b} K(c, t, x(t)) \mathrm{d} t
$$


for all $c \in[a, b]$. Then the existence of a solution to (22) is equivalent to the existence of fixed point of $T$. Indeed, by utilizing (23)-(25), we have

$$
\begin{aligned}
& d(T x, T y) \\
& =\left(\left\{\int_{a}^{b}\left|\int_{a}^{b} K(c, t, x(t)) \mathrm{d} t-\int_{a}^{b} K(c, t, y(t)) \mathrm{d} t\right|^{p} \mathrm{~d} c\right\}^{1 / p},\right. \\
& \left.\left\{\int_{a}^{b}\left|\int_{a}^{b} K(c, t, x(t)) \mathrm{d} t-\int_{a}^{b} K(c, t, y(t)) \mathrm{d} t\right|^{p} \mathrm{~d} c\right\}^{1 / p}\right) \\
& =\left(\left\{\int_{a}^{b}\left|\int_{a}^{b}[K(c, t, x(t))-K(c, t, y(t))] \mathrm{d} t\right|^{p} \mathrm{~d} c\right\}^{1 / p},\right. \\
& \left.\left\{\int_{a}^{b}\left|\int_{a}^{b}[K(c, t, x(t))-K(c, t, y(t))] \mathrm{d} t\right|^{p} \mathrm{~d} c\right\}^{1 / p}\right) \\
& \preceq\left(M\left\{\int_{a}^{b}\left|\int_{a}^{b}\right| x(t)-\left.\left.y(t)\right|^{p} \mathrm{~d} t\right|^{p} \mathrm{~d} c\right\}^{1 / p},\right. \\
& \left.M\left\{\int_{a}^{b}\left|\int_{a}^{b}\right| x(t)-\left.\left.y(t)\right|^{p} \mathrm{~d} t\right|^{p} \mathrm{~d} c\right\}^{1 / p}\right)=\left(M(b-a)^{1 / p}, 0\right) \\
& \cdot\left(\int_{a}^{b}|x(t)-y(t)|^{p} \mathrm{~d} t, \int_{a}^{b}|x(t)-y(t)|^{p} \mathrm{~d} t\right) \\
& =\varphi(d(x, y)) \text {, }
\end{aligned}
$$

where $\varphi(w)=\left(M(b-a)^{1 / p}, 0\right)\left(w_{1}^{p}, w_{2}^{p}\right)$ and $w=\left(w_{1}, w_{2}\right) \epsilon$ A.

It is easy to get that $\varphi$ is a weak comparison and $T$ is a weak $\varphi$-contraction. Accordingly, all the conditions of Theorem 20 are satisfied and then $T$ has a unique fixed point in $L^{p}[a, b]$. In other words, the integral equation (22) has a unique solution in $L^{p}[a, b]$.

\section{Conflicts of Interest}

The authors declare that there are no conflicts of interest regarding the publication of this paper.

\section{Authors' Contributions}

All authors have equal contribution in writing this paper. All authors read and approved the final paper.

\section{Acknowledgments}

The research was partially supported by the Funding Program of Higher School Outstanding Youth Scientific and Technological Innovation Team in Hubei Province of China (no. T2014212).

\section{References}

[1] F. E. Browder, Nonlinear Functional Analysis, Spring-Verlag World Pub. Cor., 1980.

[2] H. Poincaré, "Sur un théorème de géométrie," Rendiconti del Circolo Matematico di Palermo, vol. 33, no. 1, pp. 375-407, 1912.
[3] S. Banach, "Sur les opérations dans les ensembles abstraits et leur application aux équations intégrales," Fundamenta Mathematicae, vol. 3, pp. 133-181, 1922.

[4] L.-G. Huang and X. Zhang, "Cone metric spaces and fixed point theorems of contractive mappings," Journal of Mathematical Analysis and Applications, vol. 332, no. 2, pp. 1468-1476, 2007.

[5] H. Aydi, E. Karapınar, and Z. Mustafa, "Coupled coincidence point results on generalized distance in ordered cone metric spaces," Positivity, vol. 17, no. 4, pp. 979-993, 2013.

[6] H. Aydi, H. K. Nashine, B. Samet, and H. Yazidi, "Coincidence and common fixed point results in partially ordered cone metric spaces and applications to integral equations," Nonlinear Analysis. Theory, Methods \& Applications. An International Multidisciplinary Journal, vol. 74, no. 17, pp. 6814-6825, 2011.

[7] H. Aydi, B. Samet, and C. Vetro, "Coupled fixed point results in cone metric spaces for $\omega$-compatible mappings," Fixed Point Theory and Applications, vol. 2011, article no. 27, 2011.

[8] M. Dordević, D. Đorić, Z. Kadelburg, S. Radenović, and D. Spasić, "Fixed point results under c-distance in tvs-cone metric spaces," Fixed Point Theory and Applications, vol. 2011, article 9, 2011.

[9] S. Janković, Z. Kadelburg, and S. Radenović, "On cone metric spaces: a survey," Nonlinear Analysis. Theory, Methods \& Applications. An International Multidisciplinary Journal, vol. 74, no. 7, pp. 2591-2601, 2011.

[10] W. Shatanawi, E. Karapınar, and H. Aydi, "Coupled coincidence points in partially ordered cone metric spaces with a $c$-distance," Journal of Applied Mathematics, vol. 2012, Article ID 312078, 15 pages, 2012.

[11] V. Berinde, Contracții Generalizate și Aplicaţii, vol. 22, Editura Cub Press, Baia Mare, Romania, 1997.

[12] I. A. Rus, "Generalized contractions," in Seminar on Fixed Point Theory, vol. 3, pp. 1-130, 1983.

[13] I. A. Rus, Generalized Contractions and Applications, Cluj University Press, Cluj-Napoca, Romania, 2001.

[14] H. Liu and S. Xu, "Cone metric spaces with Banach algebras and fixed point theorems of generalized Lipschitz mappings," Fixed Point Theory and Applications, vol. 2013, article no. 320, 2013.

[15] H. Huang and S. Radenović, "Common fixed point theorems of generalized Lipschitz mappings in cone $b$-metric spaces over Banach algebras and applications," Journal of Nonlinear Sciences and Applications. JNSA, vol. 8, no. 5, pp. 787-799, 2015.

[16] H. Huang and S. Radenović, "Some fixed point results of generalized Lipschitz mappings on cone $b$-metric spaces over Banach algebras," Journal of Computational Analysis and Applications, vol. 20, no. 3, pp. 566-583, 2016.

[17] H. Huang, S. Radenović, and G. Deng, "A sharp generalization on cone b-metric space over Banach algebra," Journal of Nonlinear Sciences and Applications. JNSA, vol. 10, no. 2, pp. 429-435, 2017.

[18] H. Huang, S. Xu, H. Liu, and S. Radenović, "Fixed point theorems and $T$-stability of Picard iteration for generalized Lipschitz mappings in cone metric spaces over Banach algebras," Journal of Computational Analysis and Applications, vol. 20, no. 5, pp. 869-888, 2016.

[19] S. K. Malhotra, J. B. Sharma, and S. Shukla, "Fixed points of $\alpha$-admissible mappings in cone metric spaces with Banach algebra," International Journal of Nonlinear Analysis and Applications, vol. 9, no. 1, pp. 9-18, 2015. 
[20] S. Shukla, S. Balasubramanian, and M. Pavlović, "A generalized Banach fixed point theorem," Bulletin of the Malaysian Mathematical Sciences Society, vol. 39, no. 4, pp. 1529-1539, 2016.

[21] W. Rudin, Functional Analysis and its Applications, McGrawHill, New York, NY, USA, 1991. 


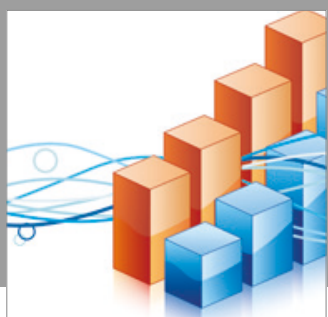

Advances in

Operations Research

vatersals

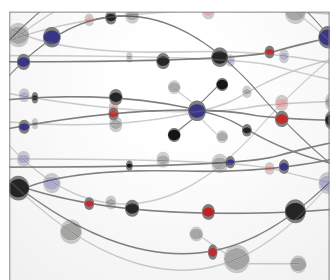

\section{The Scientific} World Journal
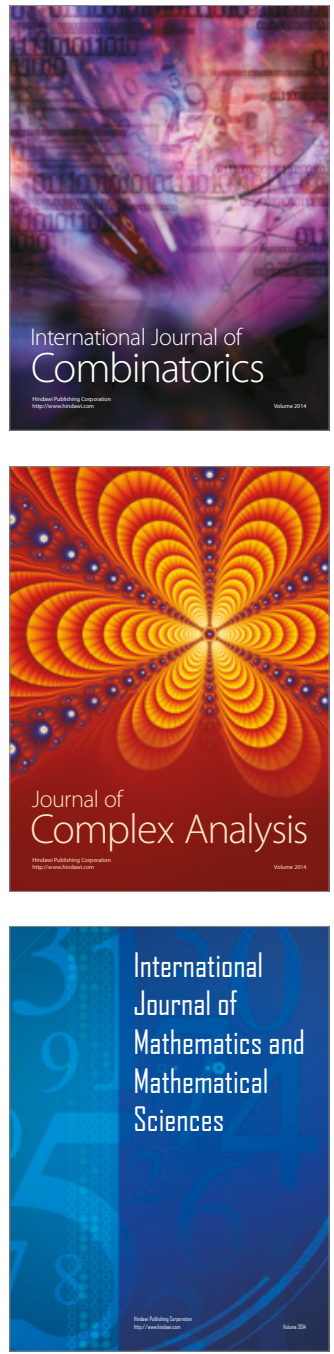
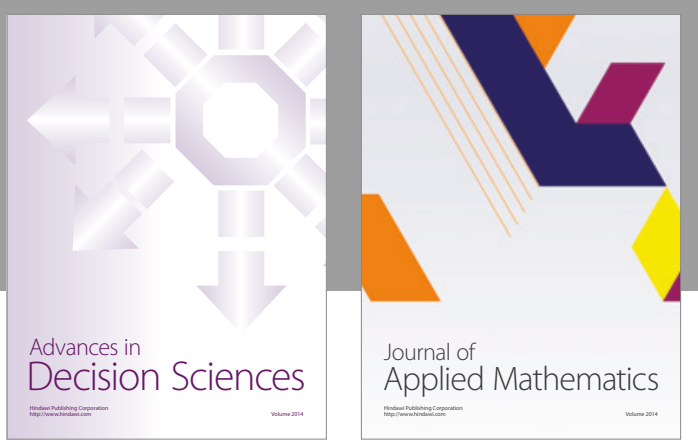

Algebra

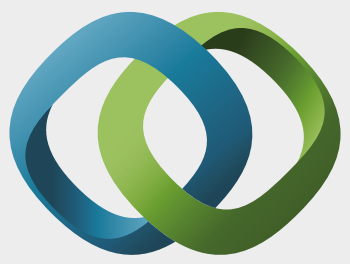

\section{Hindawi}

Submit your manuscripts at

https://www.hindawi.com
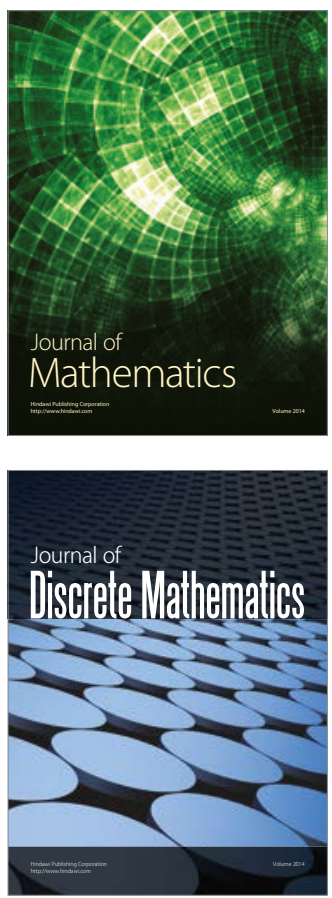

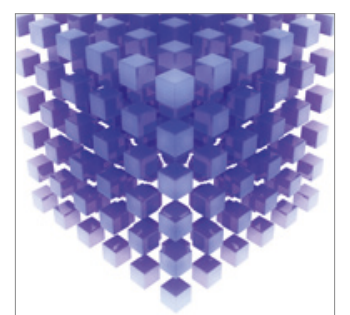

Mathematical Problems in Engineering
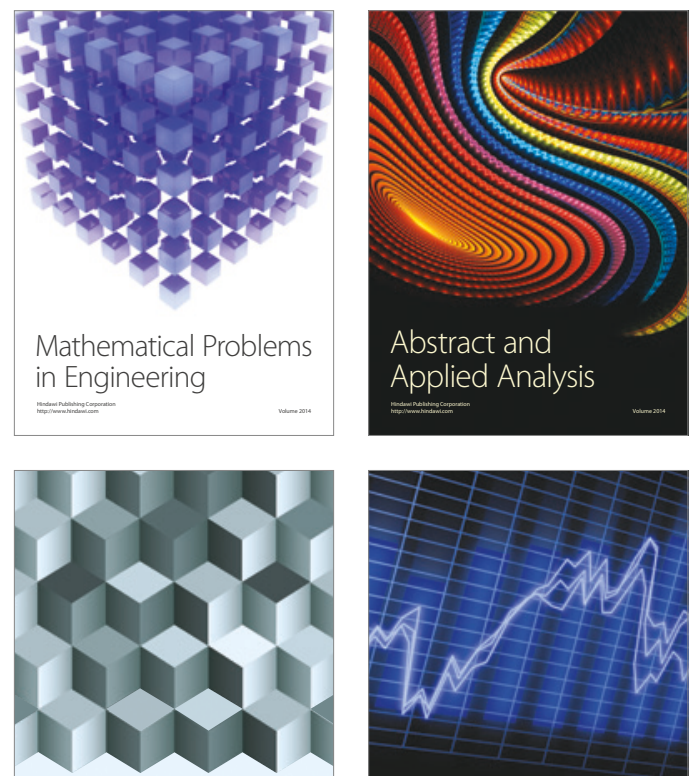

Journal of

Function Spaces

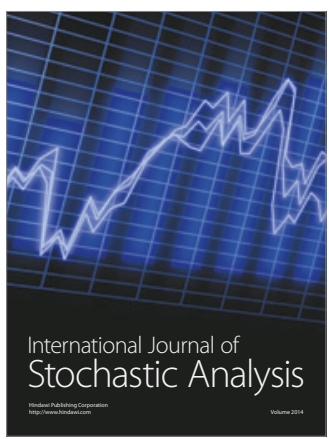

Probability and Statistics
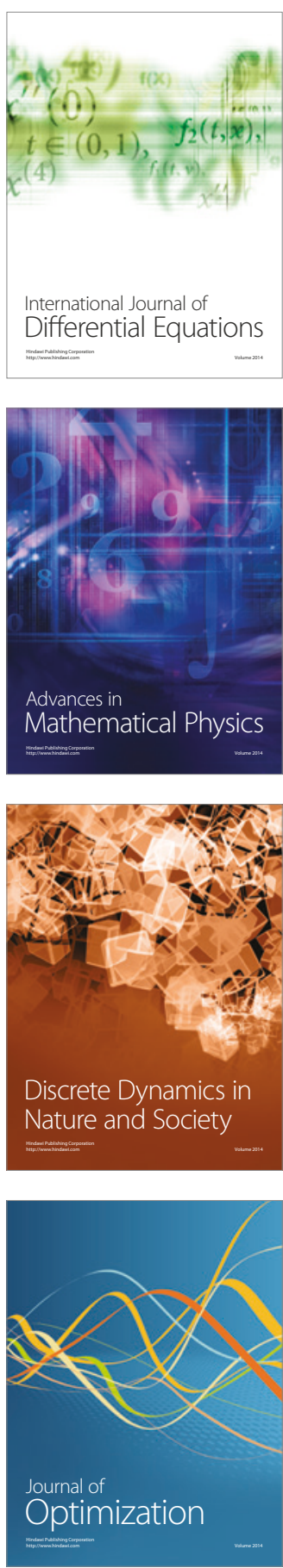